\title{
Conservative Management versus Emergency Hysterectomy in Cases of Morbidly Adherent Placenta a Retrospective Cohort Study
}

\section{Elkhateeb R*}

Lecturer at Faculty of Medicine Minia University, Egypt

*Correspondling author: Reham Elkhateeb, Lecturer at Faculty of Medicine Minia University, Egypt

Received: February 18, 2018; Accepted: March 23, 2018; Published: April 19, 2018

\begin{abstract}
Aims: To evaluate the outcome of two different approaches of management for morbidly adherent placenta (MAP).

Methods: Retrospective study analyzing the outcomes of conservative (leaving the placenta in-situ) and emergency hysterectomy of cases with MAP in one year. Patients who were referred to hospital emergency unite with suspected MAP. Emergency preparation of operative theatre and blood booking, emergency CS was done with attendance of senior obstetrician, anaesthetist, haematologist and paediatrician. Patients with placenta precreta and/or low parity the decision was to leave placenta in-situ. Other cases emergency hysterectomy was done. Data of intra-operative and post operative details were extracted from patient files and analyses of different outcomes were done.
\end{abstract}

Results: during the study period 88 patients with suspected MAP referred to maternity hospital as emergency cases (active uterine contraction or active bleeding).There was significant reduction in the intraoperative blood loss in conservative management group ( $570 \mathrm{vs.} 3760 \mathrm{ml} \mathrm{P}<0.001)$, number of blood units transfused ( 0.9 vs. $4.5, P<0.001)$, incidence of bladder injury ( 0 vs. $29.2 \%$, $\mathrm{P}<0.0001)$. There was one case of maternal mortality in the control group and none in the conservative group.

Conclusion: conservative management of MAP is significantly safer than surgical approach in patients wishing to preserve their uteri and when there invasion of surrounding organs and should be offered as the first option for these groups of patients if it is possible without endangering maternal life.

Keywords: Morbidly Adherent Placenta; Hysterectomy; Conservative Management

\section{Introduction}

Morbidly adherent placenta (MAP) which includes placenta accreta, increta and percreta is a serious obstetric complication caused by varying degrees of abnormal placental invasion at the implantation site [1]. It is known that uterine scarring is one of the most important risk factors for MAP and in the last two decades the incidence of MAP has markedly increased due to a global trend of higher rate of repeat caesarean deliveries with rising rate of placenta praevia/accreta [2,3].

Morbidly adherent placenta poses serious management challenges for obstetricians in MAP due to the high incidence of major life threatening hemorrhage. This compounded by scarring and adhesions from previous obstetric surgery and need for further surgical interventions as uterine devascularisation (e.g. uterine and internal iliac artery ligation) and/or emergency hysterectomy further accentuate the morbidity and mortality of the condition [4]. Women with MAP are also at higher risk of delivering preterm babies with higher rates of neonatal intensive care (NICU) admission, perinatal morbidities and mortality [5,6].

There is currently no universal consensus as regards the optimal management for MAP. Management options include caesarean hysterectomy without any attempts for removal of placenta, conservative management with preserving the uterus and leaving the placenta in situ and extirpative management with trying to remove the placenta manually from the uterus: An approach that carries a great risk of massive bleeding and might lead to permanent fertility loss [7].

A subset of patients with MAP is however very keen to avoid caesarean hysterectomy if possible. Given these patients' wishes and high morbidities described previously with surgical management of MAP there has been a growing interest recently in assessing the benefits and risks of conservative management of MAP as compared with the standard approach of planned caesarean hysterectomy.

Sometime we have a little choice when you faced with emergency CS referred to emergency unite without preoperative documented diagnosis of MAP.

The aim of this study was to compare the impact of the conservative and surgical management strategies for morbidly adherent placentae on maternal morbidity and mortality.
Austin J Obstet Gynecol - Volume 5 Issue 5 - 2018

Submit your Manuscript | www.austinpublishinggroup.com

Elkhateeb. () All rights are reserved
Citation: Elkhateeb R. Conservative Management versus Emergency Hysterectomy in Cases of Morbidly Adherent Placenta a Retrospective Cohort Study. Austin J Obstet Gynecol. 2018; 5(5): 1110. 


\section{Patients and Methods}

This was a retrospective cohort study in Minia Maternity University Hospital (MMUH), a large tertiary maternity unit in Egypt with over 10000 deliveries per year.

The study included all patients with MAP who were referred to emergency unite of MMUH in the period from 01/01/2013 to $31 / 12 / 2014$

\section{Eligibility criteria}

Patients were included in the study if they have been diagnosed intraoperatively with MAP and/or referred for emergency caesarean delivery without documented preoperative diagnosis of MAP.

We have excluded patients who have been diagnosed prenatally with documented MAP and opted to have planned elective caesarean hysterectomy with no wishes to preserve fertility or had an emergency caesarean hysterectomy due to major ante partum hemorrhage.

\section{Outcome Measures}

\section{Primary outcome: Maternal morbidity and mortality}

Secondary outcome: Amount of intra operative blood loss, need for blood transfusion, number of unite received, ICU admission, duration of hospital stay.

Long term follow-up for fertility outcomes for conservative management group were not pursued in this study as most patients were intending use of contraception and/or breast feeding for periods of about 2 years before considering any future pregnancies

\section{Diagnosis of MAP}

The ultrasound features used for suspicion of MAP were as described previously in literature [8] including one or more of the following;

-Loss or thinning $(<1 \mathrm{~mm})$ of the normal hypo-echoic retroplacental myometrial plane. Thinning or disruption of the hyperechoic uterine serosa bladder interface- Presence of multiple placental lakes.

Because all cases were emergency, there was no time to confirm diagnosis .our hospital has well experienced radiologist who can interpret the MRI features used to diagnose placenta accreta/percreta [9]. But there was no sufficient time to confirm diagnosis by MRI.

Management: Emergency call of senior obstetrician, anaesthetist, and haematologist, nursing staff, paediatrician and sometimes urologist attended if there was bladder or ureteric injury .wide bore IV access line, bladder catheter, emergency blood investigations and blood booking and high risk consent .patients were transferred to operative theatre for emergency CS after emergency US.

Intra operative if placenta was percreta and /or patient is low parity with no active bleeding, the decision was conservative management which included leaving the placenta in situ with no tentative attempt of removal, cutting the umbilical cord short until spontaneous resorption with bilateral uterine artery ligation, These patients were managed weekly with B-HCG level and pelvic ultrasound scan with clinical assessment for secondary PPH and sepsis in the first 6 weeks and fortnightly till 4 months postpartum. No patients in this group received methotrextate injection or antibiotic treatment. Surgical management group: Emergency caesarean hysterectomy was done in any other cases.

The choice among the two approaches was made according to patient intra operative bleeding, degree of invasion, parity, availability for follow-up if conservative approach chosen as well as the opinion/ preference of the individual consultants who performed the surgery.

\section{Data collection}

We retrospectively reviewed the medical records of all patients diagnosed with intraoperative signs of MAP referred to emergency unite of MMUH in the study period who fulfilled our inclusion criteria. Data regarding baseline characteristics of patients including maternal age, body mass index, parity, number of previous caesarean deliveries, other obstetric and/or medical co morbidities and gestational age at delivery were extracted. Intraoperative and postoperative data were extracted. This included estimated blood loss, need for blood transfusion and number of blood units transfused, bladder and other visceral injuries, approach followed either during primary surgery or within the first week after first surgery (early hysterectomy) or later than first week postoperatively (late hysterectomy) other outcomes as admission to intensive care unit, length of hospital stay, postoperative sepsis and secondary PPH in the conservative managed group and maternal mortality were also collected.

The study was approved by our institutional review board as methodologically and ethically acceptable.

\section{Study registration number: MUH15107.}

Approval date: 5/01/2015.

The reporting of this study followed the recommendation of the STROBE statement and guidelines on reporting on observational studies [10].

\section{Statistical methodology}

Data were analyzed using Statistical Package for Social Science version 21 (SPSS Inc, Chicago, USA). Data were described in terms of mean \pm SEM (standard error of the mean) for continuous variables and frequencies (number of cases) and percentages for categorical data. Independent Student's t-test was used to compare quantitative variables and Chi square test was used to compare categorical data. A $P$ value $<0.05$ was considered significant.

\section{Results}

In the study period a total of 21354 women delivered in MMUH. Patients with MAP who diagnosed intra operative and fulfilled the inclusion criteria were 88 cases. All patients in this study had previous caesarean deliveries and placenta praevia in association with suspected MAP.

There were no statistically significant differences regarding the baseline characteristics of patients in the conservative and surgical management groups as shown in (Table 1).

With regards the intraoperative and postoperative outcomes, three cases underwent hysterectomy in the conservative group (7.5\%) and all of them needed the procedure more than one week after the caesarean delivery; two cases due to sepsis and one case due to massive 
Table 1: Demographic features and risk factors in the study population.

\begin{tabular}{|c|c|c|c|}
\hline & $\begin{array}{l}\text { Conservative management group } \\
\qquad(n=40)\end{array}$ & $\begin{array}{l}\text { Surgical management group } \\
\qquad(n=48)\end{array}$ & $P$ value \\
\hline Age & $33.2 \pm 1.3$ & $34.1 \pm 1.2$ & 0.74 \\
\hline BMI & $31.7 \pm 0.9$ & $30.9 \pm 1.4$ & 0.61 \\
\hline Parity & $4.8 \pm 0.8$ & $5.1 \pm 0.7$ & 0.62 \\
\hline \multicolumn{3}{|l|}{ Previous CS n (\%) } & \multirow{4}{*}{0.54} \\
\hline 1 & $9(22.5 \%)$ & $11(22.9 \%)$ & \\
\hline 2 & $13(32.5 \%)$ & $15(31.3 \%)$ & \\
\hline$\geq 3$ & $18(45 \%)$ & $22(45.8 \%)$ & \\
\hline Prior classical, $\mathrm{T}$ or $\mathrm{J}$ uterine incision & $2(5 \%)$ & $3(6.25 \%)$ & 0.78 \\
\hline Time since last CS(years) & $2.3 \pm 0.2$ & $2.4 \pm 0.2$ & 0.86 \\
\hline Gestational age at time of delivery & $37.1 \pm 1.5$ & $36.4 \pm 1.6$ & 0.91 \\
\hline
\end{tabular}

Data presented as mean \pm SEM or frequency and percentage.

Table 2: Comparison of operative variables between the two groups.

\begin{tabular}{|c|c|c|c|}
\hline & $\begin{array}{l}\text { Conservative management group } \\
\qquad(n=40)\end{array}$ & $\begin{array}{l}\text { Surgical management group } \\
\qquad(n=48)\end{array}$ & $P$ value \\
\hline Estimated blood loss & $570 \pm 170$ & $3760 \pm 220$ & $<0.001^{*}$ \\
\hline Operation duration (min) & $76.3 \pm 8.9$ & $145.8 \pm 12.3$ & $0.02^{*}$ \\
\hline No. of patients requiring blood transfusion & 17 & 46 & $<0.01^{*}$ \\
\hline Packed red blood cell transfusion & 2 & 9 & $0.003^{*}$ \\
\hline Fresh frozen plasma & 1 & 15 & $<0.001^{*}$ \\
\hline Platelets & 0 & 7 & $<0.001^{*}$ \\
\hline \multicolumn{4}{|l|}{ Devascularization techniques used: } \\
\hline -Uterine artery ligation (n) & 40 & & \\
\hline -Hypogastric artery ligation (n) & 5 & 21 & $0.01^{*}$ \\
\hline Coagulopathy (DIC) & 0 & 12 & $<0.001^{*}$ \\
\hline
\end{tabular}

Data are presented as mean \pm SEM.

*Statistically significant difference.

secondary PPH. There was significant reduction in the intraoperative blood loss $(570 \mathrm{ml} \pm 170$ vs. $3670 \pm 220, \mathrm{P}<0.001)$ and need for blood transfusion $(17$ vs. $46, \mathrm{P}<0.01)$ in the conservative group as compared with the surgical managed group $(\mathrm{P}<0.001)$.

There were 14 cases of bladder injuries in the surgical managed group (29.2\%) it is relatively high number but it occurred incidentally during trial to dissect bladder downward to remove placental tissue adherent to anterior uterine wall and /or posterior bladder wall but no cases in the conservative group $(\mathrm{P}=0.0003)$. There was one case of maternal mortality in the surgical management group due to severe intraoperative bleeding resulting in irreversible shock and multiorgan failure. No cases were lost to follow-up in the conservative group higher rate of secondary PPH (3/40) as well as non-significant higher rate of postpartum sepsis ( 2 cases in conservative group versus none in the surgical management group). Outcome measures in both groups are shown in (Table 2 and 3 ).

The median duration till complete resorption of the placenta was 93 days \pm 3.3 days. There were no reported cases of gestational trophoblastic disease and normal menses were resumed in 21/25 $(84 \%)$ patients (in those who were not lactating, not using hormonal contraception or had late hysterectomy) after $71.3 \pm 5.4$ days.

\section{Discussion}

In the Middle East and many developing countries women tend to have large families. Desire to have large families with increase rate of CS deliveries is a dangerous combination. The number of previous caesarean section deliveries is directly proportional to the risk of developing morbidly adherent placenta. This put the Obstetrician in debate to reduce maternal morbidity and prevent mortality as possible and in the same time try to preserve uterus. The conservative approach with leaving the placenta in situ awaiting for spontaneous resorption in our study was associated with less cases of intraoperative bleeding, less need for blood transfusion, less case of bladder and visceral injury and as compared with the surgical management.

As we know there is lack of orientation about importance of ANC, economic shortage, lack of experience of primary health care provider and poor resources in most of primary and secondary care centers which lead to late diagnosis and referral of most of high risk cases.

To our knowledge this is the largest single centre report in literature on the outcomes of conservative management of MAP. Previous studies have reported varying results on rate of hysterectomy and other morbidities with conservative approach with one study from France reporting hysterectomy rate of 19.3\% [11] and another from the UK reporting a rate of $65.6 \%$ [12]. A number of smaller studies and case reports have also reported on the safety of conservative management [13-18]. 
Table 3: Postoperative outcome in the two groups.

\begin{tabular}{|c|c|c|}
\hline & Conservative management group (n= 40) & Surgical management group (n= 48) \\
\hline Blood transfusion (units) & $0.9 \pm 0.4$ & $4.5 \pm 1.2$ \\
\hline Bladder injury & 0 & $14(29.2 \%)$ \\
\hline Ureteric injury & 0 & $1(2.08 \%)$ \\
\hline Bowel injury & 0 & $0.0003^{*}$ \\
\hline Postpartum sepsis & $2(5 \%)$ & 0.56 \\
\hline Reoperation(first 24 hours) & 0 & 0.36 \\
\hline Length of hospital stay(days) & $3.2 \pm 0.7$ & $0.01^{*}$ \\
\hline ICU admission & $2(5 \%)$ & $5(10.4 \%)$ \\
\hline Anesthetic complications & $1(2.5)$ & $4.1 \pm 0.8$ \\
\hline VTE complications & 0 & $18(37.5 \%)$ \\
\hline Maternal mortality & 0 & $3(6.25 \%)$ \\
\hline
\end{tabular}

Data are presented as mean \pm SEM

*Statistically significant difference.

In the largest review on conservative management of MAP it was shown that this approach can be effective and fertility can be preserved. This review however reported on a heterogeneous conservative management approaches including use of adjuvant methotrexate, uterine artery embolization or no additional treatment [19]. Due to lack of adequate data on safety and efficacy most professional bodies currently recommend elective hysterectomy as the standard management of patients with MAP with conservative approach chosen in carefully selected group of patients wishing to preserve fertility $[20,21]$. Whilst hysterectomy remains the standard approach for the general obstetric population, our data confirms that conservative management with no additional use of methotrexate or uterine artery embolization is a safe and effective alternative option for patients with MAP wishing to preserve their fertility and should be use over emergency surgical approach. The feasibility of conservative approach if diagnosis confirmed preoperatively will require adequate preoperative counseling of patients, minimal intraoperative hemorrhage [22]. In this study the cause of secondary PPH and hysterectomy in the conservative management group was mainly due to sepsis therefore it is possible that safety of this approach can be further enhanced by the use of prophylactic antibiotic coverage to reduce risk of sepsis. It is possible that other adjuvant interventions to conservative management as use of methotrexate or uterine artery embolization will further increase risk of sepsis without any increase in safety of efficacy of this approach therefore we do not currently believe that should be part of the conservative management. This however would need to be assessed in further studies.

There was one case of maternal mortality in the surgical management group. This case was 37 years old patient who had previous 4 caesarean deliveries and had two living female offspring. She underwent emergency caesarean section at 36 weeks gestation referred to hospital with intractable hemorrhage. Trail to remove the uterus was associated with severe intraoperative bleeding control of bleeding was impossible. Bilateral uterine and hypogastric arteries ligation were done to control bleeding.. Patient was transferred postoperatively to the ICU. However, bleeding persists from the stump which necessitated re-operation after two hours. At that time, patient was shocked and intravenous dopamine infusion was administered to maintain circulation. DIC was clinically evident. In the $2^{\text {nd }}$ operation, trial to leave pelvic temponad was done. Marked adhesions between the lower uterine segment and the bladder were encountered and bladder injury occurred that was repaired by the urology team. Patient was transferred again to the ICU and was ventilated. Cardiac arrest occurred after 30 minutes and resuscitation failed. Patient received 35 units of blood and 12 units of FFP in total. The estimated blood loss in that case was 14.2 Liters.

The strength of this study is the large number of patients reported and adequacy of follow-up until full resolution of placenta and reporting on clinically important outcome

On the other hand our study may have selection and verification bias due to retrospective nature of the study and the lack of histological confirmation of placenta accreta in the conservative group. We could not also report on long term outcomes of fertility and menstrual cycles in these patients as most patients were planning contraception and delay of any future pregnancies by over 2 years. In our cohort of patients with MAP who were conservatively managed we have not detected any cases of gestational trophoblastic disease and although the latter is a rare occurrence after term pregnancy it remains a real concern and larger studies or systematic review of studies in literature may be needed to assess the potential risk of this outcome.

In conclusion, conservative management of MAP is associated with lower maternal morbidities and mortalities as compared with surgical management in patients who fits the inclusion criteria and wants to preserve their fertility. With good selection of patients who want to preserve fertility, conservative management is the first option but take in mind that preservation of the uterus not at the expense of patient life. Long term follow up studies are required to assess the subsequent fertility in patients that underwent the conservative.

\section{Funding}

This study is part of a research plan of Maternity hospital Minia University. Research is not funded by any organization.

\section{Availability of data and materials}

Data can be shared to identify the best management of similar cases in presence of facilities shortage. 


\section{Ethics approval and consent to participate}

The study was approved by our institutional review board as methodologically and ethically acceptable.

Study Registration number: MUH15107.

Approval date: 5/01/2015.

\section{References}

1. Brace $V$, Kernaghan D, Penney G. Learning from adverse clinical outcomes: Major obstetric haemorrhage in Scotland, 2003-05. BJOG. 2007; 114: 13881396.

2. Oyelese $Y$ and Smulian JC. Placenta previa, placenta accreta, and vasa previa. Obstetrics and Gynecology. 2006; 107: 927-941.

3. Gurol-Urganci I, Cromwell DA, Edozien LC, Smith GC, Onwere C, Mahmood TA et al. Risk of placenta previa in second birth after first birth cesarean section: A population-based study and meta-analysis. BMC Pregnancy Childbirth. 2011; 11: 95

4. Olive E, Roberts C, Algert C, and Morris J. Placenta praevia: Materna morbidity and place of birth. Australian and New Zealand Journal of Obstetrics and Gynaecology. 2005; 45: 499-504

5. Rosenberg T, Pariente G, Sergienko R, Wiznitzer A, Sheiner E. Critical analysis of risk factors and outcome of placenta previa. Archives of Gynecology and Obstetrics. 2011; 284: 47-51.

6. Schneiderman $\mathrm{M}$ and Balayla $\mathrm{j}$. A comparative study of neonatal outcomes in placenta previa versus cesarean for other indication at term. Journal of Maternal-Fetal and Neonatal Medicine. 2013; 26: 1121-1127.

7. Eller A, Porter T, Soisson P, Silver R. Optimal management strategies for placenta accretes. BJOG. 2009; 116: $648-654$.

8. Calì G1, Giambanco L, Puccio G, Forlani F. Morbidly adherent placenta Evaluation of ultrasound diagnostic criteria and differentiation of placenta accreta from percreta. Ultrasound Obstet Gynecol. 2013; 41: 406-412.

9. Lax A1, Prince MR, Mennitt KW, Schwebach JR, Budorick NE. The value of specific MRI features in the evaluation of suspected placental invasion. Magn Reson Imaging. 2007; 25: 87-93.

10. Von Elm E, Altman D, Egger M, Pocock SJ, Gotsche PC, Vandenbrouck JP. The Strengthening of the Reporting of Observational studies in Epidemiology (STROBE) statement: Guidelines for reporting of observational studies. Journal of clinical epidemiology. 2008; 61: 344-349.
11. Bretelle F, Courbiere B, Mazouni C, Agostini A, Cravello L, Boubli L, et al. Management of placenta accreta: Morbidity and outcome. Eur J Obstet Gynecol Reprod Biol. 2007; 133: 34-39.

12. Fitzpatrick KE, et al. The management and outcomes of placenta accreta, increta, and percreta in the UK: A population-based descriptive study. BJOG. 2014; 121: 62-70

13. Sentihes L, Resch B, Clavier E, Marpeau L. Expitaive or conservative management for placenta accreat? Am J Obst Gynecol. 2006; 195: 18751876.

14. Tongs S, Tay K, Kwek Y. Conservative management of placenta accretes: Review of three cases. Singapore Med J Case Report. 2008; 49: 156-159.

15. Diop AN1, Bros S, Chabrot P, Gallot D, Boyer L. Placenta accreta: urologic complication after successful conservative management by uterine embolization: A case report. Am J Obst Gynecol. 2009; 201: 7-8.

16. Kayem G, Anselem O, Schmitz T, Goffinet F, Davy C, Mignon A, Cabrol D. Conservative versus radical management in cases of placenta accrete: A historical study. J Gynecol Obstet Biol Reprod. 2007; 36; 680-687.

17. Shekhar S, Chauhan N, Singh K, Sharma C, Surya M. Delayed and successful manual removal of abnormally adherent placenta necessitated by uterine sepsis following conservative management with adjuvant methotrexate- a rewarding clinical experience. SAJOG. 2003; 19: 19-21.

18. Russo M, Krenz E, Hart S, Kirsch D. Multidisciplinary approach to the management of placenta accreta. Ochsner J 2011; 11: 84-88.

19. Timmermans S, Van Hof AC, Duvekott JJ. Conservative management of abnormally invasive placentation. Obstet Gynaecol surv. 2007; 62: 529-539.

20. The American College of Obstetrician and Gynaecologist committee on obstetric practice. Placenta accreta a committee opinion Number 529, 2015.

21. The Royal College of obstetrician and Gynaecologist. Placenta previa placenta praevia accreta and vasa praevia: Diagnosis and management. Greentop guidline No. 27; 2011.

22. Gielchinsky Y, Rojansky N, Fasouliotis SJ, Ezra Y. Placenta accretesummary of 10 years: A survey of 310 cases. Placenta. 2002; 23: 210-214.
Austin J Obstet Gynecol - Volume 5 Issue 5 - 2018

Submit your Manuscript | www.austinpublishinggroup.com

Elkhateeb. (C) All rights are reserved
Citation: Elkhateeb R. Conservative Management versus Emergency Hysterectomy in Cases of Morbidly Adherent Placenta a Retrospective Cohort Study. Austin J Obstet Gynecol. 2018; 5(5): 1110. 